\title{
Mental Illness and Psychiatry: The 20th and Early 21st Centuries
}

\author{
Paulann Grech ${ }^{1} \&$ Reuben Grech ${ }^{1}$ \\ ${ }^{1}$ University of Malta, Malta \\ Correspondence: Paulann Grech, University of Malta, Malta. E-mail: paulanngrech@gmail.com
}

Received: August 30, 2021; Accepted: September 27, 2021; Published: September 29, 2021

\begin{abstract}
The aim of this paper is to present the opposing views and tensions that characterised the evolution of psychiatry and understandings of mental health during the 20th century and the early decades of the 21 st century. To this extent, the principal figures and entities that occupied the main fronts during these debates are presented during a description of the journey undertaken by psychiatry during the aforementioned years. Quotes from various original texts or their translations have been included in an attempt to recreate the spirit of the periods under study. This historical exploration provides further insight into the multifaceted world of mental health, its illnesses, treatments and the role of a number of influencing bodies that were crucial into shaping this discipline across the centuries.
\end{abstract}

Keywords: critical psychiatry, mental health, mental illness, psychiatry, twentieth century

\section{Introduction}

The status of mental illness during the Middle Ages and prior to the 18th century is one that triggered many questions and contemporary debates. Psychiatry has attempted to provide various explanations to that which had been perceived as mystical and bizarre. Finally, it resulted in the structuring of clinical categories and management pathways that dictate treatment and care. This paper is intended to trace the origins of mental illness and psychiatry with a focus on the concept of psychiatric diagnosis as it evolved during the 20th century and the early decades of the 21 st century. It has been divided into two parts - the first part (i) is dedicated to a historical review of psychiatric diagnosis with particular emphasis on Kraepelinian dichotomy and the Neo-Kraepelinians. The second part (ii) is constituted by a critical discussion of opposing views and tensions in relation to the validity and benefit of a psychiatric diagnostic system - here reference is made to mainstream psychiatry as well as various movements such as anti-psychiatry and critical psychiatry as well as the User Movement.

\section{i). A Brief History of Psychiatric Diagnosis}

\section{Psychoanalysis, Psychodynamics and Kraepelinian Dichotomy}

The fundamental debate and the foundations of the psychiatric discipline are rooted in the quest to define and conceptualise mental illness in an attempt to erect clear boundaries between normality and madness. In his comprehensive work about the history of psychiatry, Shorter (1997) recounted how psychoanalytic and psychotherapuetic theories dominated the post-asylum era and the biological approaches that featured in the 19th century. For more than half a century, Freud's ideas were at the forefront of explanations that tended to focus on social and non-biological explanations of symptoms related to mental illness. This approach centred around the contention that actions and thoughts are often controlled by forces that can only be explored through a process of psychoanalysis. Although the profound effect of Freud has seeped into today's psychiatry, the major critique surrounding this school of thought is that Freud's theories were simply his, because they could not be studied empirically and so lack scientific validity (Brace, 2006).

Kraepelin, a German psychiatrist, was one of the critics who shunned Freud's psychoanalytic postulations, in favour of biological and pathological understandings of mental illnesses (Kraepelin \& Diefendorf, 1902). In this way, he opted to consider mental illness as a state of predisposition to stressful events in life. This led him to contend that "so-called psychic causes - unhappy love, failure in business, overwork - are the product rather than the cause of the disease, that they are but the outward manifestation of a pre-existing condition" (Kraepelin, 1962, p.132). In addition to his studies about the use of psychiatric drugs for treatment of disorders related to the nervous system (pharmacopsychology), Kraepelin's pioneer work lies in his classification of mental illness. The first form of a classification and diagnostic system - which ultimately led to the American Psychiatric Association (APA)'s Diagnostic and Statistical Manual (DSM) is still widely in use today (Hacking, 2013). This was fuelled by Kraepelin's interest in using empirical methods in the exploration and description of mental disorders. Following 
years of observing patients and recording symptoms related to mental illness, Kraepelin introduced the innovative Kraepelinian dichotomy which initially constituted two main divisions: manic-depressive psychosis (nowadays termed bipolar disorder) and dementia praecox (later renamed as schizophrenia) (Kraepelin, 1962).

In a critical appraisal of the history of psychiatry, Decker (2007) highlighted the events that took place during the $1880 \mathrm{~s}$ and $1890 \mathrm{~s}$, when Kraepelin slowly grouped symptoms and categorised them for publication in Compendium der Psychiatrie (Kraepelin, 1962). One of Krapelin's main strengths was his prowess as a descriptive author, as seen by the colourful manner by which he described the symptoms.

Although one of the main criticisms of Kraepelin's work centres around observer bias and the validity of preconceived notions, one must note that Kraepelin was aware of the importance of experimental psychiatry and he had designed his own methods of testing mental reactions to various substances and external factors.

Notably, Kraepelin advised that psychiatrists should refrain from focusing on the origins of illness and from postulating a diagnosis but should instead focus on the observation of the symptoms and description of the manifestations (Decker, 2007, p.340). This bears resemblance to one of the pillars of contemporary psychiatry the Recovery Movement - which affords more consideration to addressing and describing symptoms rather than placing diagnosis at the hub of care (Roberts, 2011).

Decker commented that Kraepelin's view point seemed to change over time since in the fifth edition of his book Psychiatrie, he indulged in the aetiology of dementia praecox. A notable aspect about Kraepelin is that throughout the course of his life, he often reflected upon his work and even admitted that his proposed nosology was not definite and subject to scrutiny. In response to critique by Meyer, Kraepelin acknowledged a further shortcoming in that he did not review existing literature in order to substantiate his work. Following the second world war, Kraepelin's approach waned in popularity in favour of environmental and psychological movements. In particular, psychologists were required in the treatment of shell shock especially in view of the fact that psychiatrists were short in supply (Reisman, 1991) and soon after, psychotherapy was added to the discipline (Routh, 2000).

\section{The Neo-Kraepelinians}

The psychoanalytic and psychodynamic thinking that dominated the scene in the $1940 \mathrm{~s}$ was characterised by a negative perception of psychiatric diagnosis in that it could be harmful to patients (Kendler, Munoz \& Murphy, 2009). For instance, Beck, Ward, Mendelson, Mock and Erbaugh (1962) reviewed systematic studies of the reliability of psychiatric diagnosis and reported an agreement of only 54 percent for specific diagnoses. Similarly, studies by Sandifer, Pettus \& Quade (1964) and Schmidt \& Fonda (1956) revealed agreement in just half of the cases between two independent opinions on diagnosis of a group of patients. Kendell (2004) narrated how during the same period, a group of psychiatrists at Washington University were preoccupied with the fact that the psychological approach that had gained popularity lacked a scientific base. In the 1960s and early 1970s, these psychiatrists, who became known as the neo-kraepelins expressed their dissatisfaction with a discipline that seemed to be unstructured, non-medical and non-scientific. Their preoccupation with these flaws led to an echo of Kraepelin's fundamental belief that only an empirical, biologically-based evidence base can improve the outcomes for those who exhibited symptoms related to mental illness (Decker, 2007). Once again, a cautionary note against over-emphasis on aetiology was made due to the lack of knowledge about the origin and causation of most psychiatric disorders.

The culmination of these hypotheses and assumptions led to a paper published in the Archives of General Psychiatry (Feighner, Robins, Guze, Woodruff, Winokur \& Munoz, 1972). The paper outlined a review of 1000 articles which formed the background of a proposal for new criteria for psychiatric disorders. The objective of such an extensive review was to present a diagnostic system that was based on evidence as opposed to "opinion or tradition" and described by the authors of the paper as "the most efficient currently available" (Feighner et al.). In agreement, Macalpine and Hunter (1974) stated that:

The lesson of the history of psychiatry is that progress is inevitable and irrevocable from psychology to neurology, from mind to brain, never the other way round. Every medical advance adds to the list of diseases which may cause mental derangement. The abnormal mental state is not the disease, nor its essence or determinant but an epiphenomenon. This is why psychological theories and therapies, which held out such promise at the turn of the century when so much less was known of localisation of function in the brain, have added so little to the treatment understanding of mental illness despite all the effort devoted to them (p. 256).

Furthermore, the new categorisation was fuelled by the follow up of case studies and rigorous observation of the course of psychiatric illness. This was a sharp contrast to the DSM-II which centred around psychoanalysis as well as a committee's judgement and experience (Spitzer \& Fleiss, 1974). 
Klerman (1978, pp.104-105) suggested nine tenets as the basis of the neo-Kraepelinian movement:

- Psychiatry is a branch of medicine.

- Psychiatry should utilize modern scientific methodologies and base its practice on scientific knowledge.

- Psychiatry treats people who are sick and who require treatment.

- There is a boundary between the normal and the sick.

- There are discrete mental illnesses. They are not myths, and there are many of them.

- The focus of psychiatric physicians should be on the biological aspects of illness.

- There should be an explicit and intentional concern with diagnosis and classification.

- Diagnostic criteria should be codified, and a legitimate and valued area of research should be to validate them.

- $\quad$ Statistical techniques should be used to improve reliability and validity.

As a result of this movement, the DSM-II was revised and its revolutionary sequel was produced as directed by the influential psychiatrist Robert Spitzer (Decker, 2007). The DSM system has paved the way for a modern diagnostic system and its use has spread widely in the field of psychiatry. However, subsequent publications were characterised by opposing views that challenge validity and reliability, especially in the most recent launch of the $D S M V$. In Kendler et al.'s words: “There is, we suggest, a healthy dialectical tension between nomothetic (lawbased) and ideographic (individual case) approaches to psychiatry and between scientific exp

lanation and psychological understanding" (Kendler et al., 2009).

This tension shall be explored in the next section as part of the critique of the concept of a psychiatric diagnostic system and its implications.

\section{ii). Diagnostic criticism: a matter of pseudo-science?}

Diagnostic criteria have indeed been the subject of controversy (Summerfield, 2008). Diverse perceptions have ranged from an exclusively clinical psychiatric model of diagnosis to theorists who posited that psychiatry and its alleged ability to diagnose disorders is simply a fabrication or a myth.

The psychiatric model proposed by Spitzer and colleagues that has been described in the previous section has found some acceptance and the DSM series has now reached its fifth publication (APA, 2014). Similarly, the psychiatric diagnostic system proposed by the World Health Organisation (WHO) as seen in the International Classification of Diseases (ICD) manual, is now in its eleventh edition.

The psychiatric model that features in the DSM 5 and the ICD 11 continues to have both critics and advocates. One of the critics - Summerfield (2008) - discussed the significance of culture - a case in point being the South African ailment of thinking too much which has similar symptoms to depressive disorder but a different meaning in this particular culture. This led Summerfield (2008) to state that "Western psychological discourse is setting out to instruct, regulate, and modernise, presenting as definitive the contemporary Western way of being a person. It is unclear why this should be good for mental health in Africa or Asia" (p.993).

In an exploration of some of the debates surrounding the medical model, Szasz (2010) described how diagnostic subjectivity, the boundaries of normality, coercion, conceptual disputes about the mind and brain, freedom and other human rights have generated the anti-psychiatry movement that saw its rise in the $1960 \mathrm{~s}$. In their review of critical psychiatry, Bracken and Thomas (2010) explored how the contradictions and disagreements in psychiatry which gave rise to the anti-psychiatry movement during the 1960s and 1970s, still feature in the contemporary mental health field, having now progressed to a critical psychiatry perspective and most recently a postpsychiatry viewpoint. In a parallel fashion to this movement, groups of ex-patients have expressed their dissatisfaction with mainstream medicine by forming survivor groups. These are often characterised by a quasi-militant approach to the psychiatric discipline by a group of individuals who consider themselves as survivors of traumatic and oppressive medical practice (Wallcraft \& Bryant, 2003). These movements and groups, as well as other prominent ones, shall be explored in further detail in this section.

The aim of this section of the review is not that of indulging in a crusade against conventional psychiatry. Instead, some of the main debates and movements that characterise the mental health field shall be discussed and critiqued.

\section{The antipsychiatry movement}

Desai (2005) noted that despite the emphasis on regarding psychiatry as a branch of medicine, it is characterised by striking differences from the other areas found within medical practice. As a case in point, the idea of anti- 
cardiology, for instance, is not plausible, whereas the area of anti-psychiatry is a well-defined movement that has a definite place in society. One may relate this to the historical Cinderella status of psychiatry. However, on further thought, such open hostility towards psychiatry, such as that expressed by Thomas Szasz, may well be led by the lack of tacit evidence regarding the practices of this discipline:

This view rests on a serious, albeit simple, error: it rests on mistaking or confusing what is real with what is imitation; literal meaning with metaphorical meaning; medicine with morals. In other words, I maintain that mental illness is a metaphorical disease (Szasz, 2007, p.6).

The works by Szasz and other prominent figures in the anti-psychiatry movement, such as R.D. Laing and David Cooper, shall be explored in further detail in a later part in this section of the review.

In a series of papers dedicated to the evidence-base of psychiatry, critical psychiatrists Bracken and Thomas (1999) scrutinised the medical model that has been prominent in unearthing the aetiology of a number of psychological disturbances. The authors postulated that an error may have been made when the medical model was extensively applied to all forms of psychological disturbances in a quest to prove that these symptoms were part of a specific mental illness that had a physical basis and could be treated likewise. In their publications, Bracken and Thomas mentioned schizophrenia as a typical example and labelled it as the raison d'être of psychiatry - a disorder that has been researched and stripped of human experience in order to form a biomedical picture. They also reasoned that although neuroscientific advances may fill the evidence gap, accurate and practical diagnostic tests are still fantasies that have yet to be actualised. Hence diagnosis is still mainly reliant on professional observation making it susceptible to subjective bias and political influence. Bracken and Thomas (1999) identified the power imbalance that the medical model creates within the therapeutic alliance and stated that there is a need for "a fundamental shift in the power relationship between doctor and patient. Psychiatry has to hand over responsibility for psychosis to those who experience psychosis. Those who experience psychosis must be prepared to accept that responsibility" (para. 4).

In one of his works about learning difficulties and society, Goodley (2001) expressed similar misgivings about the notion of power that characterises the Social Model of Disability and Impairment. He contended that "society creates disablement and is the arbiter of disciplinary powers that (re)produce pathological understandings of different bodies and minds" (p.210). In the same paper, Goodley (2001) elaborated on support interventions found within a continuum of deficit at one end and capacity at the other end. This views individuals with learning difficulties in terms of levels of competence/ incompetence and of a model based on pathology, problems and incapability.

The anti-psychiatry movement, which began to form in the 1960s, mirrored this observation and raised several questions pertaining to the perceived robustness of the newly constructed psychiatric discipline (Desai, 2005). Prior to delving deeper into the diagnostic challenge, the history of the anti-psychiatry movement is going to be explored with focus on the main phases and viewpoints that characterise this movement.

Desai (2005) described how the first of the major steps in the anti-psychiatry direction was taken by a science fiction writer, L. Ron Hubbard, who, in 1950, founded the Church of Scientology (p.185). In 1969, the Citizens Commission of Human Rights (CCHR) was founded by scientology in an attempt to unveil the perceived evils practiced by psychiatry: "to expose and eradicate the brutalization of patients in the name of 'mental health'. Over the years, the Citizens Commission has investigated and exposed thousands upon thousands of cases of psychiatric negligence, abuse and brutality" (Scientology.org, 2014).

Hubbard's preoccupation with what he clearly perceived as being barbaric practice was communicated through a number of his publications. He believed that psychiatry is a worldwide conspiracy run by the Union of Soviet Socialists Republic (USSR). A critical point regarding these assumptions follows the power issues that seem to lie behind such claims. It is felt that while Hubbard's attack on psychiatry's lack of consideration for the spiritual aspect may be well placed, whether scientological practices have a positive outcome on the course of mental illnesses has yet to be proven. Cases such as the notorious one of Lisa McPherson who was brought dead to hospital following introspection rundown - a scientological spiritual technique that attempts to treat florid psychosis, fuels doubt in this regard (Kendell et al., 2004).

The second wave of the antipsychiatry movement saw the involvement of professionals such as psychiatrists and sociologists who questioned the basis of psychiatric diagnosis and treatment as well as the coercive authority linked to it (Desai, 2005). Adolf Meyer had been one of the earliest 20th century leading figures who opposed the use of diagnostic criteria as a primary and sole means of diagnosing mental illness. Contrasting with similar movements that challenged conventional psychiatry, Meyer did not distinguish between mental disturbances that should be dealt with by the medical profession and those that should be treated as social problems (Meyer, 1952). 
Echoing the views of other radicalists such as Szasz (1974), Meyer (1952) endeavoured to explain schizophrenia in terms of maladaptation to life experiences and an unhealthy lifestyle: "living in ways which put their mind and the entire organism and its activity in jeopardy" (p.4).

One of Meyer's concerns was that psychiatric practice lacked scientific evidence (Meyer, 1952). In order to partially address this issue, he postulated reaction-type systems that served the purpose of a structured analysis of abnormal responses and remarked that psychiatry should be more organised and disciplined. He proposed a classification system that was "a wide range of facts usually left to untrained common-sense, but now available as a more and more organised body of facts, methods of study and methods of therapeutic procedure" (Meyer, 1952, III, 44). Meyer's scepticism regarding any diagnostic system as complete or as a steadfast rule featured in his works - he even described his own system as not being "sufficiently settled for practical purposes" (vol. II, p.136).

The base of Meyer's contention, which is one of today's debates in psychiatry, holds that the medical model focuses too much on bodily parts, namely the brain, and is generally reluctant to seek connections to the lived experience of the individual. Meyer (1952) shunned the over-inflated importance of statistical research techniques and emphasised that a higher level of insight can be obtained through person research. An interesting point that was specifically argued by Meyer (1952) was that the primary aim of the psychiatrist needs to be that of collecting the facts and not to produce a diagnosis: "If the facts do not constitute a diagnosis we must nevertheless act on the facts" (II, 146). He cautioned against the obsession with making a diagnosis that is often aimed to satisfy the psychiatrist's craving for tying up the symptoms in a neatly organised parcel that is linked to a ready-made treatment package (Meyer, 1952).

In view of approaches such as that articulated by Meyer, the act of diagnosing may be understood in terms of the application of a label, leading to an erosion of an individual's identity and medicalisation of symptoms which may be caused by non-pathological factors. Yet this voice has been subjected to counterarguments by a number of service users who, through the adoption of a biological model, have found great relief in being offered a medical reason (a diagnosis) for their symptoms (Huibers \& Wessely, 2006). Despite the stigma and sick role attributed to such diagnoses, the act of having an explanation and a validation of symptoms is akin to other medical disorders and in itself, this has been a source of comfort for these individuals (Fulford, Broome, Stanghellini \& Thornton, 2005). For instance, in an article about the consequences of diagnosis, Heitler (2012), who is a clinical psychologist, described how one of her patients who used to be irritated by her feelings of anxiety gained more control over these symptoms by becoming aware of the clinical label of the state of anxiety: "By clinically labelling her feeling anxiety, she was able to use her new knowledge of what to do in the face of specific emotions" (para.20).

This argument is also exemplified by the book An Unquiet Mind - a compelling memoir by Kay Jamison (1995) who described her life as characterised by bipolar disorder. Jamison clearly portrayed her acceptance of her symptoms as situated in understandings pertaining to genetics, pathology and medical imaging results. For her, the origins are solid, organic and based on scientific evidence. This has allowed her to seek the necessary treatment and progress with her life - a successful life characterised by multiple research endeavours and a professor post at Johns Hopkins School of Medicine (Jamison, 1995).

Although criticisms of the theory and practice of psychiatry such as those expressed by Meyer have been evident throughout the nineteenth and twentieth century, it was the South African psychoanalyst David Cooper who introduced the term anti-psychiatry. He stated how "a more profound questioning has led some of us to propose conceptions and procedures that seem quite antithetic to the conventional ones - in fact what may be regarded as a germinal anti-psychiatry" (Cooper, 1967, p.ix).

In a similar manner to Meyer, Cooper favoured a psychosocial approach to the origin of mental illness and attributed disorders to a dysfunctional family system. He argued that in the family, permissible behaviour is regulated through complex double-binds - this is a type of political control of the members. An interesting tangent raised by Cooper involves his view that madness is in fact a process of restructuring. He argued that if this process is not interfered with, the person can emerge from the experience with gains above his pre-morbid level of functioning: "Madness is a permanent revolution in the life of a person...a deconstitution of oneself with the implicit promise of return to a more fully realized world" (Cooper, 1967, pp.37,51).

Cooper's views seemed to echo in two simultaneous attacks on conventional psychiatry, as presented by psychoanalyst R.D. Laing and psychiatrist Thomas Szasz. Huddleston (2006) described how Laing's work featured in 1960 when following his medical training with the army, he began to doubt the use of placing psychiatric patients in deep insulin comas as well as the use of electroconvulsive therapy. It was instantly clear that his position was that of viewing mental illnesses as a normal reaction by sensitive individuals to a mad world: 
If the human race survives, future men will, I suspect, look back on our enlightened epoch as a veritable age of Darkness. They will presumably be able to savor the irony of the situation with more amusement than we can extract from it. They will laugh on us. They will see that what we call 'schizophrenia' was one of the forms in which, often through quite ordinary people, the light began to break through the cracks in our all-too-closed minds (Laing, 1967, p.107).

He also ventured into comparing determinism to the more beneficial approaches of subjectivity and freedom and emphasised that cure can only happen when the individual is left free to choose. Laing's first book, namely: The Divided Self involved case studies that were used to challenge the notion of schizophrenia. In doing so, Laing (1960) revolutionised the way that mental illness is perceived and interpreted, particularly by arguing that psychosis is not a biological ailment but a normal reaction in the face of ontological insecurity. The latter term refers to insecurities related to one's existence and to an individual who is not able to "take the realness, aliveness, autonomy and identity of himself and others for granted" and who then embarks on a mission to avoid "losing his self" (Laing, 1960, pp.41-3). Laing structured this contention on the theory that our existence in the world is defined by mental models carried by ourselves about those around us. He theorised that psychosis arises when there is tension between our private inward persona and the model that we present to the world, which leads to a division of the self, as a defence mechanism. This split is characterised by the classical symptoms of schizophrenia. Using his case studies and sociograms as evidence, Laing discovered that the bizarre and inexplicable symptoms exhibited by patients often make sense when they are viewed against the backdrop from which they emerge.

Applying the concept of The Double Bind Theory by Bateson, Jackson, Haley and Weakland (1956), Laing (1960) elaborated on the fact that in malfunctioning family systems, a child can find themselves in a situation where, in order to enjoy parental affection and approval, they have to comply to a self-identity that has been constructed by their parents (p.191). This is usually different from how the child internally experiences themselves to be, which results in a dilemma and a potential psychotic response.

In his later work Sanity, Madness and the Family, Laing and Esterson (1964) explored how individuals interact and how this may relate to schizophrenia. Essentially, this described the notion of schizophrenogenic families and included sharp criticism on the way in which institutions such as schools oppress individuals by attempting to mould their thoughts and feelings in a way that is dictated and accepted by society. In Self and Others, Laing (1961) discussed the terms "phantasy" and "unconscious experience" which refer to the latent, internal authentic lived experience which cannot be observed by others but can only be inferred through discussion:

I think of me being inside my body and at the same time the inside of my body being somehow 'inside' my private space. If someone comes into my room unasked he does not intrude upon me to the same extent as if he were to enter my body without permission. However since I am inside my body, my body is also outside me in some peculiar sense (p.18).

The determination to challenge the validity and reliability of psychiatry was shared by psychologist and lawyer D.L. Rosenhan, whose 1973 sensational article, published in the prestigious journal Science was cited and quoted in debates that followed. This article - On Being Sane in Insane Places - was intended to indicate that American psychiatrists did not have scientific diagnostic standards and that an individual's stay in a psychiatric hospital was an irrational experience. These views had been tested by a fascinating observational study carried out by the researcher in order to demonstrate that false diagnosis is a very real possibility in psychiatric settings.

The study featured Rosenhan and seven other 'normal' people who went to different psychiatric hospitals on an individual basis in order to attempt to be admitted. The reason that they gave for their admission request was that they were hearing voices that said "empty", "hollow", and "thud" (Rosenhan, 1973). These invented symptoms were ones that had never featured in psychiatric diagnosis, yet, in each case, the "pseudopatients" were falsely diagnosed as suffering from a psychiatric disorder which merited admission (Rosenhan, 1973, p.383). As soon as the pseudopatients were admitted, they started to behave 'normally' and did not report any further symptoms. The task that each individual had was to try to convince the staff that $\mathrm{s} / \mathrm{he}$ had recovered and so could be discharged. The striking results showed that even though the pseudopatients had been admitted on a voluntary basis and were behaving in a perfectly normal manner, Rosenhan and his collaborators were admitted for an average of 19 days (Rosenhan, 1973). In one case, the admission period was nearly two months. Furthermore, upon discharge, the 12 individuals were labelled as "schizophrenia in remission" and this was entered into their permanent medical record. Thus, they were never certified as having truly regained their sanity (Rosenhan, 1973). Interestingly, Rosenhan asked the study participants to take field notes about their interactions with staff members and it was instantly noted that the professionals attempted to "depersonalize" patients and avoid significant interactions with them. For instance, the pseudopatients kept a count of the responses that they were given when they approached staff 
members to ask questions. It could be noted that an alarmingly high number of professionals refused to make eye contact when approached or spoken to (Rosenhan, 1973). Rosenhan's critics outlined various limitations related to the ethical and methodological rigour in the study such as, for instance, Rosenhan's possible inclination to inflate the negative aspects of the participants' experiences inside the psychiatric hospital.

Simultaneously, Szasz started to harshly question the existence of mental illness in relation to its comparison to medical disorders. Szasz (2007) argued that the main difference between medicine and psychiatry can be explained by the fact that in generic medicine, disorders were discovered whereas it seemed that in psychiatry, they were simply invented (p.xv). This made them "counterfeit diseases" and "non-diseases": "If you talk to God, you are praying; If God talks to you, you have schizophrenia" (Szasz, 1973, p.101). He hypothesised that these myths were perpetuated by the state and by psychiatrists' wish to safeguard their profession and preserve their power and control: "the state is primarily an apparatus of coercion with a monopoly of the legitimate use of violence" (Szasz, 2007, p.151).

Szasz's example can be taken to a further level by noting that one of the concepts in psychiatry is that of insight this refers to a person's ability, or lack of, to recognise that s/he is suffering from a mental illness (Markova \& Berrios, 1992). It may not be inaccurate to note that this does point towards a situation where a person's failure to comply with mainstream psychiatric ideas may be at risk of simply being written off as lack of insight. On exploring the concept of insight in relation to recovery, Timimi (2012) noted that "paradoxically, it has been found that the presence of this type of "insight" (meaning accepting you are mentally ill and need medical treatment) is negatively correlated with emotional well-being, economic satisfaction and vocational status" (sec. Prognosis).

Szasz's description of the notion that modern psychiatric experts invent diseases does not seem too far-fetched in view of the ever-expanding, seamless boundaries of the current systems of classification. This argument was one of many that were introduced by Frances (2009) in his criticism of the DSM 5. In what has been widely considered as one of the best arguments against conventional psychiatric practice, Szasz's book: The Myth of Mental Illness shunned the generally accepted view that mental illness is like any other bodily illness and medical speciality (Szasz, 1974). The author's critique revolved around the fact that symptoms attributed to mental illness are simply imitations due to the fact that if an ailment has to be classified as a true disease, then it has to be considered with and compared to the rest of medical practice (Szasz, 1974). This refers to measurement and testing in a scientific fashion as well as pathological demonstration at the cellular or molecular level. This is a vivid contrast to how mental illnesses had been historically voted into existence by agreement amongst members of the APA - and the subsequent shaping of diagnostic labelling:

Every science consists of classification, control, and prediction; hence to prove psychiatry is a science, the psychiatrist classifies, controls, predicts. The result is that he classifies people as mad; that he confines them as dangerous (to themselves or others); and that he predicts people's behaviour, robbing them of their free will and hence of their very humanity (Szasz, 1973, p. 115).

Szasz (1960) contended that although the manifestation of mental disturbances may resemble pathological diseases, they are simply but wholly, problems in living and in morality: "Our adversaries are not demons, witches, fate, or mental illness. We have no enemy whom we can fight, exorcise, or dispel by 'cure'. What we do have are problems in living — whether these be biologic, economic, political, or sociopsychological” (p.115).

Another area that held the focus of Szasz's criticism was involuntary mental hospitalisation. In a 2006 documentary film called Psychiatry: An Industry of Death, Szasz emphasised that involuntary mental hospitalization is a crime against humanity which can easily result in "pharmacratic" dictatorship (CCHR, 2005). This view shares a number of similarities to Foucault's critique of the penalty system and the self-regulation process induced by constant supervision. Foucault's works shall be explored in further detail later in this section but as a final note, it has to be added that Szasz's views also resemble Foucault's in the sociological origin of mental illness. For instance, Szasz (1970) discussed how "in the past, men created witches: now they create mental patients" (p.xxiv). Similarly, in Madness and Civilisation, Foucault (1961/2013) noted that:

Leprosy disappeared, the leper vanished, or almost, from memory; these structures remained. Often, in these same places, the formulas of exclusion would be repeated, strangely similar two or three centuries later. Poor vagabonds, criminals, and "deranged minds" would take the part played by the leper (p.5).

It has to be noted that, as described in an article by Buchanan-Parker and Barker (2009), Szasz has often been misinterpreted. In fact, he has been frequently wrongly associated with the anti-psychiatry movement of the 1960s and 1970s. Szasz (2009) himself pointed out that he is only opposed to the practice of coercive psychiatry - on the other hand, he is in favour of a contractual psychiatric service between consenting adults with no involvement of 
the state. Moreover, in his book Antipsychiatry: Quackery Squared, he criticised the anti-psychiatry movement and regarded it as an imitation of psychiatry:

Antipsychiatrists imitated psychiatrists by means of a childish negativism: they constructed antitheories of schizophrenia, which they called 'existential-phenomenological accounts of madness', established anti-hospitals, which they called 'households' and defined as 'ideal psychiatric communities' and provided psychiatric treatment which they called 'trips', that often entailed the use of mind-altering (psychotropic) drugs (Szasz, 2009, p.4).

As discussed by Bracken and Thomas (2010), one of the outstanding characteristics of Szasz's writing is its clarity - this serves to add coherence and consistency to his analysis and his attempt to demystify psychiatric diagnostic labelling. On the other hand, his form of thinking has been criticised as being too rigid and that it may have been misinterpreted as being an attack on the concept of mental illness (Double 2010). Furthermore, Double (2010) contended that one should be careful when making such harsh statements against psychiatry because mental health services are still needed and specific diagnoses may help to address and alleviate one's suffering through giving meaning to a group of symptoms. He added that the problem arises when diagnostic categories are simply regarded as biomedical concepts that omit the psychological and social aspects during assessment and care planning.

Echoing Szasz's critics, it has to be noted that whereas some of the earlier DSM versions simply involved a committee's consensus on voting psychiatric disorders into existence, the APA (2013) described how nowadays such illnesses are tested in a scientific manner that is supposedly more rigorous. Still, it seems as if this scientific method itself may not be appropriate, as articulated in the response given by the Society for Humanistic Psychology to the publication of the DSM 5. The society's view is that the proposed diagnostic criterion is largely based on social norms and on subjective judgments:

The putative diagnoses presented in DSM-V are clearly based largely on social norms, with 'symptoms' that all rely on subjective judgments, with little confirmatory physical 'signs' or evidence of biological causation. The criteria are not value-free, but rather reflect current normative social expectations (Society for Humanistic Psychology, 2014, Divison 32, sec.9).

This enhances the risk of medicalising responses that are based on normal variations rather than pathology - these responses may require help but not necessarily psychiatric help:

Clients and the general public are negatively affected by the continued and continuous medicalization of their natural and normal responses to their experiences; responses which undoubtedly have distressing consequences which demand helping responses, but which do not reflect illnesses so much as normal individual variation (Society for Humanistic Psychology, 2012, Divison 32, sec.9).

The constitution of evidence that serves as the base of psychiatric knowledge shall be explored in further detail in a later part of this section. In a counterargument that advocates the medical model, it has to be noted that the history of generic illnesses resembles that of mental illnesses due to the fact that before aetiology and treatment were understood, management was generally ineffective. This implies that psychiatric disorders are part of a field that is still evolving and so it may be more accurate to consider them as misunderstood rather than as non-existent. However opposing arguments hold that the problem is much more serious and related to deep cracks in the facade of modern psychiatry (Angell, 2011).

Desai (2005) described how the third major antipsychiatry force originated from England in the 1970s. This was led by the Mental Patients Union which consisted of those who called themselves survivors of psychiatry. The union was also influential within a larger movement, namely the World Network of Users and Survivors of Psychiatry. In a similar manner to their predecessors, activists sought to deny the existence of mental illness and the cold and clinical manner of psychiatric practice. Irwin, Mitchell, Durkin and Douieb (2011) published a rare cope of The Fish Pamphlet which may have been the starting point of the British Survivor Movement in 1974:

Psychiatry is one of the most subtle methods of repression in advanced capitalist society. Because of this subtlety, few recognise the dangers shrouded by the mystification of 'modern medicine'. The psychiatrist has become the High Priest of technological society, exorcising the 'devils' of social distress, by leucotomy (butchery of the brain), electric shock treatment - ECT (plugging brains into mains), and heavy use of mind-controlling drugs. The mental patient is a sacrifice we make whilst we continue to serve the Gods of the Capitalist Religion (p.23).

Noorani (2013) explained how the movement was particularly successful in improving the nature of psychiatry by bridging the gap between service providers and service users. This shall be explored in more detail in the following section. 


\section{The User Movement}

Notably, many critical service user/ survivor movement groups have emerged as a result of the antipsychiatry move (Wallcraft, Reed \& Sweeney, 2003). Examples of these groups include Survivors Speak Out, Mad Pride, Mad Women, National Self Harm Network and the Hearing Voices Network. The main objectives of these groups is advocacy and to provide a consultancy service to mainstream mental health services. Additionally, they favour a political stance whereas professionals in areas of health care are urged to relinquish paternalistic manners of addressing mental illness and instead focus on sharing knowledge and power with those who seek their service (Noorani, 2013). The magazine Asylum serves as an exhibition of works that echo the main tenets of the user movement:

A consultant once said to me that he wanted to increase my medication. I asked him to state his reasons: Was it to iron out or flatten highs and lows in my thoughts, because I could get quite manic? The doctor said that was not the case, and that was paranoia on my part. I replied that the reason I had said that was not because I knew it to be true, but that I was just speculating, to see if the doctor would agree or disagree, or offer another reason. In effect, it was playing with words or indulging in a mild form of trickery, so as to harmlessly get some information. It was interesting to see how quickly the doctor jumped to the wrong conclusion, due to the psychiatrists' mindset towards their patients. I then explained what I was doing by asking him that, and the doctor laughed, especially when I pointed out that he may be the one suffering from paranoia. Of course I was joking. How many patients are misdiagnosed and on the wrong amounts of medication because of misunderstandings between them and their doctors? Many, I would suggest. And how many are labelled paranoid when they can't express themselves as I did? Once again, many (Anonymous user in a medium-secure unit, 2011, p.9).

In 2003, a report named On Our Own Terms which was based on research carried out by the English service user/survivor movement was published (Wallcraft, et al., 2003). This publication consisted of a detailed survey on the consistency, operating procedures and future plans of the multiple groups within the movement. A number of findings outlined the important activities that were being undertaken by groups within the movement. For instance, education and training were popular activities within groups:

We are going to be doing some work around relapse prevention, not a term I particularly like, a piece of jargon. It's a model from the States, it's much more a social model which treats people as individuals. People have their own plan that they go through training to develop, so it's very much around self-management and taking responsibility yourself for your own signs of distress and what you do about them. The person is at the centre of it, but it includes services as well as individual things and people's own strategies as well. They will go on to train professionals in using it so it moves up from there (Wallcraft et al., 2003, p.16).

The experience of being a member of this movement was explored by Knight and Kierans (2011) who carried out a narrative inquiry with five members of user movement groups in order to elicit the rationale and the meaning of participation. Interestingly enough, being part of a service user movement group was perceived as creating a sense of community and solidarity due to the experience of engaging with people who have had similar experiences:

And I got on there...everybody had the same feelings as me ... 'this is wrong, we've not been treated properly', and for me that was so empowering because it was like a whole online community that was together and so there was this sense of community (Knight \& Kierans, 2011, slide 6).

On an individual basis, it had an additional empowering effect whereby some of the members who were interviewed reported that due to their participation, they became aware that they wanted to move out of feeling like a "user", which is connoted to disenabling implications:

Do I stay 'user' or this person down here, or do I make major changes, and start looking at this process of stopping being this disabled, disenabled person.... and I just went for it, and became self-employed (Knight \& Kierans, 2011, slide 9).

This consequently led to another beneficial outcome which was that of helping others in the same situation. Another reason was the pride experienced by being a change agent within a mental health system that was perceived as being harmful and ineffective:

It has been a vital part of my recovery and it's been a vital part of feeling something, a purpose in life, there is a purpose in my life beyond my immediate family and everything, that there's, I am actually doing something useful, that really is very, very important (Knight \& Kierans, 2011, slide 14).

One criticism of survivor movement groups has been based on the observation that despite their value in giving a voice to the person who is experiencing mental difficulties, there may be a lack of representation. This is due to the fact that service user groups seem to be mainly made up of people who have had negative experiences in 
relation to their mental health as well as to the services that they sought (Wallcraft et al., 2003). Anger seems to be a common catalyst within group members. Furthermore, it has to be acknowledged that other factors such as gender, age, sexuality and culture contribute directly to the experience of mental illness and these need to be adequately represented in the movement groups.

\section{Critical psychiatry and post psychiatry}

Alongside the emergence of the user movement, contemporary interpretations of the experience of mental illness have carved a competing niche to the biomedical model which has held prominence for countless years. These emerging viewpoints ranged from the logical and humane to that which is somewhat bizarre and perhaps even risky. As an example, one particular explanation of mental illness by the American psychologist Louis A. Sass, may be seen as being particularly intriguing and somewhat different from the biological and sociological explanations that have been explored so far in this review. In his book Madness and Modernism: Insanity in the Light of Modern Art, Literature, and Thought, Sass (1992) elaborated on why schizophrenia remains a mysterious condition. Primarily, Sass (1992) argued that madness results due to "confrontation". This confrontation entails a human's realisation that his existence is a framework that facilitates interpretation of the world. In usual circumstances, the individual is not consciously aware of this phenomenon or of the fact that reality is constantly being constructed in a particular manner. A state of hypersensitivity and hyperalertness, often seen in a psychotic state, may be symptomatic of this "confrontation". In this sense, it is erroneous to view "madness" as a deficit state because it is in fact a state of "hyper-realisation" (Sass 1992).

Interestingly, Sass (1992) pointed out that madness, specifically psychosis, bears a striking resemblance to art, whereas many modern artists and writers seem to be expressing very similar preoccupations as individuals who are understood as being mad. Sass progressed to list these preoccupations - these include an exploration of reality and relativism, defiance of authority, fragmentation and a total loss of self - often exhibited in the art and literature by artists such as Franz Kafka, Paul Valery, Samuel Beckett, Alain Robbe-Grillet, Giorgio de Chirico and Salvador Dali. Through the use of a phenomenological approach to explore the cognitive similarities between illness and genius, Sass (1992) referred to the tendency of both to deconstruct reality and human experience and so in a parallel manner, both states involve being in a hyper-reflexive state and a sense of alienation from the world.

In what feels like a sequel to this book, in The Paradoxes of Delusion: Wittgenstein, Schreber, and the Schizophrenic Mind, Sass (1994) presented an unorthodox view of the inside of the schizophrenic mind by comparing Daniel Schreber (a jurist who spent 13 years in asylums due to mental illness) and Ludwig Wittgenstein (a central philosopher in twentieth century thought). Sass (1994) contradicted the conventional view of schizophrenia as a disease and pictured it as another means of viewing reality rather than as a treatable or suppressible condition:

The standard conceptions, whether psychoanalytic or psychiatric have nearly always presupposed the Western's enduring equation of sanity with reason, insanity with passion and error - as if madness were necessarily a kind of stupidity or dementia, or in terms of Plato's famous metaphor, a case of the wild horse of instinct overwhelming the charioteer's conscious control (p.10).

Instead of interpreting the symptoms of schizophrenia through a biomedical lens, Sass (1994) opted for a philosophical approach that analyses subjective and objective realities as well as how we judge these reality types. Reflecting on Sass' work, Bracken and Thomas (1999) asserted that this is a serious contention since in psychiatry, schizophrenia is considered a dogma and questioning its existence as an illness has the potential to shake the very foundations of this discipline. In a typical postmodernist view, these same authors pointed out that one has to be cautious when proposing the denial of the existence of psychosis or when picturing it as a wonderful experience of self-discovery. This is due to the fact that reality has shown that oftentimes, it is an extremely distressing and debilitating condition. However, medicine should refrain from promoting psychiatric understandings and medical treatment as absolute and ideal solutions since these tend to de-humanise the experience:

Unlike the antipsychiatrists, we do not deny the existence of psychosis, nor do we seek to romanticise it as a journey of self-discovery. For most people psychosis is a terrifying, perplexing experience. But the medical model has failed in its task to account for psychosis, and in doing so it has wrenched the ownership of the experience from the sufferers, denying them their own attempts to make sense out of the experience (Bracken \& Thomas, 1999, para. 3).

Figures such as Patrick Bracken and Philip Thomas are the main protagonists in critical psychiatry and postpsychiatry. Other leading figures are Joanna Moncrieff, Duncan Double, Sami Timimi and Bradley Lewis (Kecmanovic, 2009). 
A number of authors who are linked to the critical and post psychiatry period have been clear in their critical explanations about what constitutes the recent progress in psychiatry (Bracken \& Thomas, 2001). In fact, most of this progress is mainly related to the development of new drugs, neuroscience, molecular genetics and Cognitive Behavioural Therapy (CBT). The main concern here is that the components of this progress are based on assumptions that may or may not be accurate. Whilst a number of diagnostic endeavours and treatment approaches are a direct branch of the medical model, other therapies such as CBT are still rigidly rooted in beliefs about the nature of self, the environment and the construction of reality (House \& Loewenthal, 2008).

At times, it is quite clear that unlike antipsychiatry, critical and postpsychiatry are not a blatant attack on anything related to medicine and conventional psychiatry (Lewis, 2006). Alternatively, the main philosophy shifts towards respecting human autonomy and the right for choice and freedom - it is not to say that mainstream psychiatric services are not useful, desirable and effective in some cases. However, it is about the need to widen the horizon and partake a humble approach by realising that for the time being, diagnostic labelling and the explanation as well as the treatment options that it provides, are simple hypothesis and not facts; it is one way of looking at reality or rather, one way of describing reality. Thus, assuming that it is the only way or the best description of reality would be subject to error (Bracken \& Thomas, 2001). Having its philosophical roots in a postmodernist approach, critical and postpsychiatry encompass a more holistic way of addressing madness and distress. The main ideas are drawn from philosophers such as Foucault, Merleau-Ponty, Wittgenstein and Heidegger.

Despite their common goal that psychiatry needs to be practiced without the underpinning foundation in terms of brain pathology, postpsychiatry and critical psychiatry differ in a number of ways. In brief, the main difference lies in that critical psychiatry is mostly concerned with the politics and ethics of psychiatry as well as encompassing a number of philosophical positions (Thomas, 2013). In contrast, in his book Moving Beyond Prozac, DSM, and the New Psychiatry: The Birth of Postpsychiatry, Lewis (2006) described how postpsychiatry is more focussed on postmodernism and concerned with the modernist's tendency to look for technical solutions to address life's problems. According to postpsychiatry advocates, progress can be achieved by engaging with the service users in a creative manner rather than by imposing psychiatric rules on those who we call patients: "Contemporary psychiatry tends to focus on neurochemical and genetic explanations, to place technological solutions over ethical and human considerations, and to use forced treatment methods to resolve clinical controversy. By contrast, postpsychiatry works to counter these trends" (Lewis, 2006, p.x).

Some of the advocates of critical and postpsychiatry such as Phil Thomas, Patrick Bracken, Duncan Double and Joanna Moncrieff formed critical psychiatry/ psychology groups such as The Critical Psychiatry Network (UK). Originating from England, this network has spread internationally and includes multiple philosophical positions which may not all be conceptually linked to postmodernism. Activists are mainly preoccupied with the political and ethical aspects of clinical psychiatric practice as well as an effort to limit the influence of the pharmaceutical industry on psychiatry and mental health care (Double, 2002). The views on the impact of the pharmacological industry shall be discussed in a later section of this review.

An article by Kecmanovic (2009), bearing the notable title of Postpsychiatry: How to throw out the baby with the bathwater, challenged the fundamental concepts of the postpsychiatry movement. Primarily, the author argued against the insistence of advocates of postpsychiatry in de-prioritising traditional psychiatric diagnosis as this risks a distraction from understanding the problem in a holistic person-centred approach:

For example, frontal lobe tumor may underlie someone's low energy levels, depression, confusion, forgetfulness, lack of initiative and loss of interest in people and matters. Should psychiatrists first look for the meaning of such symptoms in the patient's social context, and thereby let his or her mental and most likely physical state as well deteriorate; or should they first rule out any possible physical-biological cause of the said symptoms? (Kecmanovic, 2009, p.278).

In the subsequent argument, the author reasoned that with the exception of involuntary treatment, the psychiatrist does not attempt to impose a diagnosis on a patient but simply provides advice to someone who has voluntarily sought the psychiatrist's opinion:

In a good number of cases patients do not have their own view of where their mental problems came from. (After all, that is why they look for professional assistance.) They can accept or reject the psychiatrist's interpretation, or might be indifferent towards it. If they accept it, and the results of the treatment turns out to be below the patients' expectations, patients are free to seek assistance from another psychiatrist who follows the principles of another psychiatric model (Kecmanovic, 2009, p.279).

In the cases of more severe conditions such as psychosis, which may lead to involuntary treatment, Kecmanovic (2009) then justified the imposition of the psychiatrist's diagnosis due to the fact that the patient's mental pathology 
may limit his/her ability to interpret his/her symptoms correctly. He argued in favour of this practice by describing it as being: "The same right mutatis mutandis a physician has to impose on a patient an explanation for his or her for example jaundice or bleeding, or impaired sighting that may conflict with the patient's reading of these troubles" (p.279).

Finally, Kecmanovic (2009) used Spitzer's words as the last say in this argument by sharing his view that a proposal of a joint diagnostic system between the service provider and the service user is not practical or necessary. On a critical note, it has to be said that since Spitzer was the leading figure in the production of the new DSM versions, it is hardly surprising that he seems to prefer a psychiatrist's diagnostic monopoly.

In the second part of his article, Kecmanovic (2009) addressed the issue of treatment and recovery. The author accurately described how generally, postpsychiatrists argue against the proven effectiveness of pharmacotherapy. He also elaborated on the postpsychiatry view that the term recovery is not synonymous to treatment and it does not imply a complete resolution of symptoms. Rather, it is applied to a state of being where the individual is enjoying a good quality of life enhanced by a sense of freedom and the ability to "speak out". It is rather disappointing that the building of these arguments led to a rather abrupt and short counter-argument by the author where he simply stated that experience has shown that psychosis triggers hostile reactions from society and so it has to be treated professionally. Conclusively, the author refrained from taking sides and alternatively reflected on a recommendation by Jakovljevic. This refers to the suggested use of pluralist and integrated approaches as these may be the most promising contemporary concepts of psychiatric practice (Jakovljevic, 2007 as cited in Kecmanovic, 2009).

\section{Conclusion}

The $20^{\text {th }}$ and early $21^{\text {st }}$ centuries were crucial times in the evolution of the psychiatric discipline, and they were the bridge between a dearth of knowledge in relation to mental illness to a period where the field is well-structured and better understood. Importantly, the era that followed, witnessed the release of patients from their chains and from other barbaric practices that were often forced on the individual under the name of treatment. During the $20^{\text {th }}$ and early $21^{\text {st }}$ centuries, the mental health domain was painted by a tug of war of opposing viewpoints with illness on one side of the spectrum, genius on the other, and reactions to problems in living featuring somewhere in between. It cannot be denied that opposing mainstream and radical views add fascinating dimensions to this area. Conclusively, Jakovljevic (2013) postulated that in psychiatry, there is no one unified theory and practice, but a plethora of theories and practices that range from pharmacotherapy, electrical stimulation, psychological therapies, education and life coaching:

Different schools of thought assessing mental health and mental disorders have given rise to different perspectives of psychiatry: the medical or disease perspective, and the dimensional, cognitive, behavioural, narrative, spiritual and systems perspectives. Each of these perspectives tends to analyze, understand, define and treat mental disorders in different ways, each with their own merits (p.203).

Unfortunately, this loose assembly of approaches has been the target of criticism in relation to a lack of clear pathways (Jakovljevic, 2013). However, it may also be viewed as a strength since it provides service providers and service users with various options that can be explored and tested as a matter of personal preference and effectiveness.

\section{Declarations}

Funding: This research received no specific grant from any funding agency in the public, commercial, or not-forprofit sectors.

Disclosure: The authors disclose no conflict of interest

\section{References}

Angell, M. (2014). The New York Review of Books, 58(12). Retrieved August 15, 2014 from http://www.nybooks.com/issues/2011/jul/14/

Barker, P., \& Buchanan-Barker, P. (2005). The tidal model. Hove [England]: Brunner-Routledge.

Beck, A., Ward, C., \& Mendelson, M. et al. (1962) Reliability of psychiatric diagnoses: 2. A study of consistency of clinical judgments and ratings. American Journal of Psychiatry, 119(4), 351-357. https://doi.org/10.1176/ajp.119.4.351

Brace, R. (2006). The Failure of Freud. Ukapologetics.net, Retrieved August 14, 2014 from http://www.ukapologetics.net/22truthaboutfreud.html 
Bracken, P. (2012). Psychiatric power: A personal view. Ir $J$ Psych Med, 29(1), 55-58. https://doi.org/10.1017/S0790966700017638

Bracken, P., \& Thomas, P. (1999). Let's scrap schizophrenia. Criticalpsychiatry.co.uk. Retrieved August 15, 2014 from http://www.criticalpsychiatry.co.uk/index.php?option=com_content\&view=article\&id=62:lets-scrapschizophrenia\&catid $=34$ :members-publications\&Itemid $=56$

Bracken, P., \& Thomas, P. (2001). Postpsychiatry: a new direction for mental health. BMJ: British Medical Journal, 322(7288), 724-727. https://doi.org/10.1136/bmj.322.7288.724

Bracken, P., \& Thomas, P. (2010). From Szasz to Foucault: On the role of critical psychiatry. Philosophy, Psychiatry, \& Psychology, 17(3), 219-228. https://doi.org/10.1353/ppp.2010.0007

Bracken, P., Thomas, P., \& Timimi, S. et al. (2012). Psychiatry beyond the current paradigm. The British Journal of Psychiatry, 201(6), 430-434. https://doi.org/10.1192/bjp.bp.112.109447

CCHR. (2005). Museum Targets Psychiatry as an "Industry Of Death”. PRWeb. Retrieved January 23, 2021 from https://www.prweb.com/releases/2005/12/prweb325461.htm

Cooper, D. (1967). Psychiatry and anti-psychiatry. London: Tavistock Publications.

Decker, H. (2007). How kraepelinian was Kraepelin? How kraepelinian are the neo-Kraepelinians? From Emil Kraepelin to DSM-III. History of Psychiatry, 18(3), 337-360. https://doi.org/10.1177/0957154X07078976

Desai, N. (2005). Antipsychiatry: Meeting the challenge. Indian Journal of Psychiatry, 47(4), 185-187. https://doi.org/10.4103/0019-5545.43048

Double, D. (2002). The limits of psychiatry. British Medical Journal, 324(7342), 900-904. https://doi.org/10.1136/bmj.324.7342.900

Double, D. (2010). The overemphasis on diagnosis in psychiatry. Critpsynet.freeuk.com, Retrieved August 15, 2014 from http://www.critpsynet.freeuk.com/Overemphasis.htm

Feighner, J., Robins, E., \& Guze, S. et al. (1972). Diagnostic criteria for use in psychiatric research. Archives of General Psychiatry, 26(1), 57-63. https://doi.org/10.1001/archpsyc.1972.01750190059011

Foucault, M. (2013). Madness and Civilization. New York: Random House US.

Foucault, M. (2020). Discipline and Punish. Penguin Books.

Frances, A. (2009). A Warning Sign on the Road to DSM-V: Beware of Its Unintended Consequences. Psychiatric Times, 26(8), 1-4, Available from: A Warning Sign on the Road to DSM-V: Beware of Its Unintended Consequences - See more Retrieved August 15, 2014 from http://www.psychiatrictimes.com/articles/warning-sign-road-dsm-v-beware-its-unintendedconsequences\#sthash.aVxsWDMC.dpuf

Frequently Asked Questions | APA DSM-5. (2014). American Psychiatric Association. Retrieved August 15, 2014 from http://www.dsm5.org/about/pages/faq.aspx

Fulford, K., Broome, M., \& Stanghellini, G. et al. (2005). Looking with both eyes open: fact and value in psychiatric diagnosis?. World Psychiatry, 4(2), 78-86, Retrieved from http://www.ncbi.nlm.nih.gov/pmc/articles/PMC1414736/

Goodley, D. (2001). Learning Difficulties, the Social Model of Disability and Impairment: challenging epistemologies. Disability \& Society, 16(2), 207-231. https://doi.org/10.1080/09687590120035816

Hacking, I. (2013). Lost in the Forest - DSM-5: Diagnostic and Statistical Manual of Mental Disorders, Fifth Edition by the American Psychiatric Association. London Review of Books, 35(15), 7-8, Retrieved August 14, 2014 from http://www.lrb.co.uk/v35/n15/ian-hacking/lost-in-the-forest

Harris, D. (2012). The Residents: Stories of Kingsley Hall, East London, 1965-1970 and the experimental community of RD Laing. UK: Dominic Harris.

Heitler, S. (2012). Psychological Diagnosis: Dangerous, Desirable, or Both?. Psychologytoday.com. Retrieved August 15, 2014 from http://www.psychologytoday.com/blog/resolution-not-conflict/201202/psychologicaldiagnosis-dangerous-desirable-or-both

House, R., \& Loewenthal, D. (2008). Against and for CBT. Ross-on-Wye: PCCS.

Huddleston, J. (2006). Anti-Psychiatry. Soteria.freeuk.com. Retrieved August 15, 2014 from http://www.soteria.freeuk.com/Anti-Psychiatry6.htm 
Huibers, M., Wessely, S. (2006). The act of diagnosis: pros and cons of labelling chronic fatigue syndrome. Psychological Medicine, 36(07), 895-900. https://doi.org/10.1017/S0033291705006926

Hunter, R., \& Macalpine, I. (1963). Three hundred years of psychiatry, 1535-1860. London: Oxford University Press.

Irwin, E., Mitchell, L., \& Durkin, L. et al. (2011). The need for a mental patients union - some proposals. 1st ed. In: Curtis T, Dellar R and Esther L (ed.), Mad Pride, UK: Chipmunka Publishing ltd.

Jakovljevic, M. (2013). Theoretical psychiatry: Missing link between academic and clinical psychiatry for further scientific and professional maturation of psychiatry. Psychiatria Danubina, 25(3), 203-206. Retrieved August 15, 2014 from http://www.hdbp.org/psychiatria_danubina/pdf/dnb_vol25_no3/dnb_vol25_no3_203.pdf

Jamison, K. (1995). An unquiet mind. New York, USA: A.A. Knopf.

Kecmanovic, D. (2009). Postpsychiatry: How to throw out the baby with the bathwater. Psychiatria Danubina, 21(3), 276-282, Retrieved from http://www.hdbp.org/psychiatria_danubina/pdf/dnb_vol21_no3/dnb_vol21_no3_276.pdf

Kendell, R. (2004). The myth of mental illness. In Szasz Under Fire: The Psychiatric Abolitionist Faces his Critics. Open Court, 29-55.

Kendler, K., Munoz, R., \& Murphy, G. (2009). The development of the Feighner criteria: a historical perspective. American Journal of Psychiatry, 167(2), 134-142. https://doi.org/10.1176/appi.ajp.2009.09081155

Klerman, G. (1978). The evolution of a scientific nosology. Schizophrenia: Science and practice. 1st ed. In: Shershow J (ed.), Schizophrenia: Science and Practice, Cambridge, Mass: Harvard University, pp. 99-121.

Kraepelin, E. (1962). One hundred years of psychiatry. New York: Philosophical Library.

Kraepelin, E., \& Diefendorf, A. (1902). Clinical psychiatry; A text-book for students and physicians. New York: Macmillan.

Kraepelin, E., \& Hippius, H. (1987). Emil Kraepelin: Memoirs. Berlin, etc.: Springer-Verlag.

Laing, R. (1960). The Divided Self. USA: Penguin.

Laing, R. (1961). Self and others. USA: Routledge.

Laing, R. (1967). The politics of experience. New York: Pantheon books.

Laing, R., \& Esterson, A. (1964). Sanity, Madness and the Family. London: Penguin Books.

Lewis, B. (2006). Moving beyond Prozac, DSM, \& the new psychiatry. USA: University of Michigan Press.

Markova, I., \& Berrios, G. (1992). The meaning of insight in clinical psychiatry. The British Journal of Psychiatry, 160(6), 850-860. https://doi.org/10.1192/bjp.160.6.850

Meyer, A. (1952). Collected Papers (Four Volumes). Baltimore: John Hopkins Press.

Noorani, T. (2013). Service user involvement, authority and the 'expert-by-experience' in mental health. Journal of Political Power, 6(1), 49-68. https://doi.org/10.1080/2158379X.2013.774979

Open Letter to the DSM-5. (2012). Society for Humanistic Psychology. Retrieved August 15, 2014 from $\mathrm{http}: / / \mathrm{www}$.ipetitions.com/petition/dsm5/

Reisman, J. (1991). A history of clinical psychology. New York: Hemisphere Pub. Corp.

Roberts, G. (2011). The Roots of the Recovery Movement in Psychiatry: Lessons Learned. The British Journal of Psychiatry, 198(6), 497-498. https://doi.org/10.1002/9780470682999

Rosenhan, D. (1973). On being sane in insane places. Science, 179(4070), 250-258. Retrieved August 15, 2014 from http://digitalcommons.law.scu.edu/lawreview/vol13/iss3/3

Routh, D. (2000). Clinical psychology training: A history of ideas and practices prior to 1946. American Psychologist, 55(2), 236-241. https://doi.org/10.1037/0003-066X.55.2.236

Sandifer, M., Pettus, C., \& Quade, D. (1964). A study of psychiatric diagnosis. The Journal of Nervous and Mental Disease, 139(4), 350-356. https://doi.org/10.1097/00005053-196410000-00006

Sass, L. (1992). Madness and modernism. New York, NY: Basic Books.

Sass, L. (1994). The paradoxes of delusion. Ithaca, N.Y.: Cornell University Press.

Schmidt, H., \& Fonda, C. (1956). The reliability of psychiatric diagnosis: a new look. The Journal of Abnormal 
and Social Psychology, 52(2), 262. https://doi.org/10.1037/h0046289

Shorter, E. (1997). A history of psychiatry. New York, USA: Wiley.

Summerfield, D. (2008). How scientifically valid is the knowledge base of global mental health?. BMJ: British Medical Journal, 336(7651), 992-994. https://doi.org/10.1136/bmj.39513.441030.AD

Szasz, T. (1960). The Myth of Mental Illness. American Psychologist, 15(2), 113-118. Retrieved August 15, 2014 from http://www.columbia.edu/cu/psychology/terrace/w1001/readings/szasz.pdf

Szasz, T. (1973). The second sin. Garden City, N.Y.: Anchor Press.

Szasz, T. (1974). Ceremonial chemistry. Garden City, N.Y.: Anchor Press.

Szasz, T. (2007). The medicalization of everyday life. Syracuse, N.Y.: Syracuse University Press.

Szasz, T. (2009). Antipsychiatry. Syracuse, N.Y.: Syracuse University Press.

The mental health user and survivor movement - what do people get from being involved? (2011). Knight, T. \&

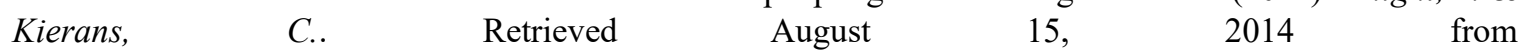
http://webcache.googleusercontent.com/search?q=cache:98P09v9Nb8IJ:www.rhodrihuws.plus.com/CPN/as ylum\%2520talk1.pptx $+\& \mathrm{~cd}=1 \& \mathrm{hl}=\mathrm{en} \& \mathrm{ct}=\mathrm{clnk} \& \mathrm{gl}=\mathrm{mt}$

Thomas, P. (2013). What is Critical Psychiatry? - Mad In America. Mad In America. Retrieved August 15, 2014 from https://www.madinamerica.com/2013/01/what-is-critical-psychiatry/

Wallcraft, J., \& Bryant, M. (2003). The mental health service user movement in England. London, UK: The Sainsbury Centre for Mental Health.

Wallcraft, J., Reed, J., \& Sweeney, A. (2003). On Our Own Terms. London, UK: The Sainsbury Centre for Mental Health.

Why is Scientology opposed to psychiatric abuses? (2014). Scientology.org. Retrieved August 15, 2014 from http://www.scientology.org/faq/scientology-in-society/why-is-scientology-opposed-to-psychiatricabuses.html

\section{Copyrights}

Copyright for this article is retained by the author(s), with first publication rights granted to the journal.

This is an open-access article distributed under the terms and conditions of the Creative Commons Attribution license (http://creativecommons.org/licenses/by/4.0/). 